\title{
Injection of immunoglobulin in the treatment process of children with severe pneumonia
}

\author{
Liping Chen ${ }^{1}$, Xuehai $Q i^{2}$, Ruiying $L i^{3}$, \\ Xudong Wang ${ }^{4}$, Baohai Shi ${ }^{5}$, Qingmei Meng ${ }^{6}$
}

\begin{abstract}
Objective: To observe the effect of intravenous infusion of immune globulin in the treatment of children with severe pneumonia.

Methods: Ninety-eight children with severe pneumonia who received treatment in our hospital between April 2015 and December 2016 were selected, and they were grouped into a control group and an treatment group, 49 each group. The control group received conventional treatment. The treatment group was additionally treated with immune globulin on the basis of conventional treatment. The humoral immune indicators were detected using immunoturbidimetric assay, and the inflammatory reaction indicators were detected using enzyme-linked immunoabsorbent kit. The overall efficacy, clinical symptoms, humoral immunity and inflammatory response were compared between the two groups.

Results: The total effective rate of the treatment group was significantly higher than that of the control group $(P<0.05)$. The cough, rale and fever of the treatment group disappeared faster than those of the control group, the relief of cardiac failure was also faster in the treatment group $(P<0.05)$. The immunoglobulin $\mathrm{G}(\mathrm{lg} \mathrm{G})$, Ig $A$ and $\lg M$ of patients in the two groups compared before treatment, and no significant difference was found $(P>0.05)$. The lg $G$ level of the treatment group was higher than that of the control group after treatment $(P<0.05)$. The comparison of $\lg A$ and $\lg M$ between the two groups indicated no significant difference $(P>0.05)$. The two groups had no significant differences in the content of tumor necrosis factor (TNF)- $\alpha$, C-reactive protein (CRP), soluble intercellular adhesion molecule (SICAM)-1 and interferon (IFN) $-\gamma(P>0.05)$ before treatment, but the content of the treatment group was significantly higher than that of the control group $(P<0.01)$.

Conclusion: Immunoglobulin was significantly effective in the adjuvant treatment of children with severe pneumonia, and it can rapidly improve the improvement of symptoms, enhance immune function and inhibit inflammatory reaction; therefore it is worth promotion.
\end{abstract}

KEYWORDS: Immune globulin, Children, Treatment, Severe pneumonia.

doi: https://doi.org/10.12669/pjms.35.4.83

How to cite this:

Chen L, Qi X, Li R, Wang X, Shi B, Meng Q. Injection of immunoglobulin in the treatment process of children with severe pneumonia. Pak J Med Sci. 2019;35(4):940-944. doi: https://doi.org/10.12669/pjms.35.4.83

This is an Open Access article distributed under the terms of the Creative Commons Attribution License (http://creativecommons.org/licenses/by/3.0), which permits unrestricted use, distribution, and reproduction in any medium, provided the original work is properly cited.

Correspondence:

Xudong Wang

No.29 Longtan Road,

Department of Pediatrics,

Tai'an City Central Hospital,

Tai'an, Shandong,

271000, China.

E-mail: xudongwangone@163.com

* Received for Publication:

* Revision Received:

* Revision Accepted:
October 28, 2018

April 25, 2019

May 5, 2019

\section{INTRODUCTION}

Severe pneumonia is a common emergency and severe respiratory disease in the department of pediatric internal medicine and a main cause for death of hospitalized infants in China. ${ }^{1,2}$ Severe pneumonia in children which is usually caused by respiratory syncytial virus infection can weaken the immune function of children; featured by acute onset and severe disease condition, it can lead to death if treatment is not performed timely. ${ }^{3}$ Severe pneumonia 
in children is characterized by systemic poisoning, which can not only severely damage the respiratory system, but also cause different degrees of damages to other systems and a series of symptoms such as water and electrolyte balance disorders and myocarditis. ${ }^{4}$ It develops quickly and usually results in death of children due to the delayed or ineffective treatment. 5,6 For the treatment of severe pneumonia in children, it is necessary to correct hypoxia, carry out active treatment and prevent complications.

In recent years, some studies have suggested that severe pneumonia in children is related to the disorder of immune function, and inhibition of humoral immune response and insufficient secretion of immunoglobulin (Ig) are important reasons for the development and poor prognosis of severe pneumonia..$^{7-9} \mathrm{Ig}$ for intravenous injection is a blood product purified from a large number of healthy human plasma, and its main ingredient is protein. Ig has functions of immunoregulation and immune substitution; therefore it has good treatment efficacy in diseases related to the immune system of children. ${ }^{10}$ Moreover it has been reported that children with severe pneumonia are prone to have systemic transitional inflammatory response which can stimulate the body to produce a large amount of pro-inflammatory cytokines, mediate local inflammatory reaction, cause severe inflammatory damages to tissues and organs, induce cytokine cascade reaction. ${ }^{11}$ This study emphatically analyzed the efficacy of intravenous injection of Ig in the adjuvant treatment of children with severe pneumonia and its influence on humoral immunity and inflammatory state.

\section{METHODS}

This study enrolled 98 children with severe pneumonia who were treated in our hospital in the period from April 2015 to December 2016. The children developed different levels of dyspnea, cyanosis and cough. X-ray films showed flaky shadows in the lung of children, and moreover the lung texture increased and dry and wet rale appeared. The 98 children were randomly divided into treatment group and a control group according to the random table method, with 49 cases in each group. There were 26 males and 23 females in the treatment group; their age ranged from 1 to 10 years (mean (5.6 \pm 2.7 ) years); 14 children had central failure, 9 children had acute cerebral edema, 11 children had microcirculation, 8 children had acidosis, and 7 children had gastrointestinal dysfunction. There were 27 males and $22 \mathrm{fe}-$ males in the control group; their age aged from one to 10 years (mean $(5.3 \pm 2.9)$ years); 13 children had central dysfunction, 8 had acute cerebral edema, 12 had microcirculation dysfunction, 9 had acidosis, and 7 had gastrointestinal dysfunction. The results were comparable as there were no statistical differences in gender, age, disease severity and physical condition between the two groups ( $\mathrm{P}>0.05)$.

Inclusive and exclusive criteria: Children who satisfied the diagnostic criteria of severe pneumonia mentioned in Guidelines for Management of Community Acquired Pneumonia in Children (revised), ${ }^{12}$ aged one month $\sim 14$ years, hospitalized in intensive care unit for more than $24 \mathrm{~h}$, had complete clinical data, and were confirmed having bacterial infection by sputum or throat swab culture rather than other pathogen infection such as virus, fungi, mycoplasma and chlamydia were included. But children who have received anticoagulant therapy before entering intensive care unit, had blood system disease or congenital coagulation system abnormality, or had malignant tumor, hypertension, diabetes or severe liver and renal diseases were excluded from this study. This study has been reviewed and approved by the ethics committee of our hospitals, and the family members of the children signed informed consent.

Treatment method: The control group received the traditional treatment, i.e. intravenous injection of azithromycin injection at a dose of $1 \mathrm{mg} / \mathrm{kg} / \mathrm{d}$, for 7 days. Moreover treatment which could relieve cough and asthma and aerosol inhalation were used.

Patients in the treatment group was given intravenous injection of Ig at a dose of $0.4 \mathrm{~g} \bullet \mathrm{kg}^{-1} \bullet \mathrm{d}^{-1}$ for three days.

(1) Evaluation of overall treatment effect: ${ }^{13}$ Treatment was evaluated as significantly effective if the symptoms and vital signs completely disappeared, urine volume significantly increased, and X-ray film suggested absorption of pulmonary lesions and strong heart sound one week after treatment. Treatment was evaluated as effective if the symptoms and vital signs improved, urine volume increased, and X-ray film suggested partial absorption of pulmonary lesions one week after treatment. Treatment was evaluated as ineffective if the symptoms and vital signs had no improvement or even aggravated, urine volume had no obvious increase, and X-ray film suggested no absorption of pulmonary lesions. The overall effective rate could be calculated using the formula: overall effective rate $=$ (number of significantly effective cases + number of effective cases)/total number of cases ${ }^{*} 100 \%$.

(2) Improvement of clinical symptoms: The improvement of clinical symptoms including 
Treatment of children with severe pneumonia

Table-I: Comparison of clinical efficacy between the two groups [n(\%)].

\begin{tabular}{|c|c|c|c|c|}
\hline Group & Significantly effective & Effective & Ineffective & Total effective rate \\
\hline Treatment group & $32(65.31)$ & $15(30.61)$ & $2(4.08)$ & $47(95.92)$ \\
\hline Control group & $25(59.02)$ & $16(32.65)$ & $8(16.33)$ & $41(83.67)$ \\
\hline$X^{2}$ & & & 9.337 & \\
\hline $\mathrm{P}$ & & & $<0.05$ & \\
\hline Group & $\begin{array}{l}\text { Disappearance } \\
\text { time of cough }\end{array}$ & $\begin{array}{c}\text { Disappearance } \\
\text { time of rale }\end{array}$ & $\begin{array}{c}\text { Disappearance } \\
\text { time of fever }\end{array}$ & $\begin{array}{l}\text { Improvement time } \\
\text { of cardiac failure }\end{array}$ \\
\hline Treatment group & $5.81 \pm 0.22$ & $5.24 \pm 0.29$ & $1.51 \pm 0.60$ & $1.10 \pm 0.65$ \\
\hline Control group & $8.61 \pm 0.72$ & $7.50 \pm 0.83$ & $3.96 \pm 0.02$ & $2.36 \pm 0.93$ \\
\hline $\mathrm{t}$ & 15.662 & 13.254 & 7.568 & 5.506 \\
\hline$P$ & $<0.05$ & $<0.05$ & $<0.05$ & $<0.05$ \\
\hline
\end{tabular}

cough, lung rale, fever and cardiac failure was compared.

(3) Detection of serum humoral immunity and inflammatory reaction indexes: Firstly $3 \sim 5 \mathrm{~mL}$ of peripheral venous blood was collected from each patient before treatment and in the $1^{\text {st }}$ week after treatment. After 15 30 $\mathrm{min}$, the blood samples were centrifuged at $3000 \mathrm{r} / \mathrm{min}$ for $10 \mathrm{~min}$. Then the upper layer of serum was carefully collected. The content of IgG, IgA and IgM was detected using immunoturbidimetry. The content of tumor necrosis factor (TNF)- $a$, C-reactive protein (CRP), soluble intercellular adhesion molecule (SICAM)-1 and interferon (IFN)- $\gamma$ were detected using enzymelinked immunoabsorbent kit.

Statistical analysis: Statistical processing was made using SPSS ver. 20.0. Categorical data were expressed by cases and processed by Chisquare test. Measurement data were expressed by Mean $\pm S D$ and processed by two-independent sample $\mathrm{t}$ test. Difference was thought statistically significant if $\mathrm{P}<0.05$.

\section{RESULTS}

The overall effective rate of the treatment group was $95.92 \%$, higher than $83.67 \%$ in the control group, and the difference had statistical significance $(\mathrm{P}<0.05$, Table-I). The cough, rale and fever of the treatment group disappeared faster than those of the control group, and the relief of cardiac failure was also faster in the treatment group $(\mathrm{P}<0.05)$; and the differences were statistically significant $(\mathrm{P}<0.05$, Table-II).

There was no significant difference in the levels of Ig $\mathrm{G}, \operatorname{Ig} \mathrm{A}$ and Ig $\mathrm{M}$ between the two groups before treatment ( $\mathrm{P}>0.05)$. The levels of $\operatorname{Ig} \mathrm{G}, \operatorname{Ig} \mathrm{A}$ and Ig M in the two groups after treatment were higher than those before treatment, and the level of Ig G in the treatment group was higher than that in the control group $(\mathrm{P}<0.05)$. The differences of the levels of IgA and IgM between the two groups had no statistical significant ( $\mathrm{P}>0.05$, Table-III).

Changes of content of inflammatory factors: Before treatment, no differences were found in the content of TNF- $\alpha$, CRP, sICAM-1 and IFN- $\gamma$ between the two groups $(\mathrm{P}<0.05)$. After treatment, the content of TNF- $\alpha$, CRP, sICAM-1 and IFN- $\gamma$ of the two groups significantly decreased $(\mathrm{P}<0.05)$, and moreover the content of the treatment group was significantly lower than that of the control group ( $<<0.05$, Table-IV).

\section{DISCUSSION}

Pneumonia is a common disease in children in China, with the highest incidence in winter and spring. Lung inflammation of children is caused by inhalation of amniotic fluid, pathogen infection and allergic reaction. The symptoms of pneumonia in children are cough, fever, dyspnea and moist

Table-III: Changes of Ig of the two groups before and after treatment.

\begin{tabular}{llccl}
\hline Group & & $\operatorname{Ig} G$ & $\operatorname{Ig} A$ & $\operatorname{Ig} M$ \\
\hline Treatment group & Before & $7.20 \pm 0.52$ & $0.46 \pm 0.13$ & $0.83 \pm 0.26$ \\
& After & $12.21 \pm 0.82^{* \#}$ & $0.56 \pm 0.14^{*}$ & $0.87 \pm 0.31^{*}$ \\
\multirow{2}{*}{ Control group } & Before & $7.19 \pm 0.51$ & $0.47 \pm 0.12$ & $0.82 \pm 0.27$ \\
& After & $11.20 \pm 0.79^{*}$ & $0.55 \pm 0.13^{*}$ & $0.86 \pm 0.30^{*}$ \\
\hline
\end{tabular}

Note: " $m e a n s ~ P<0.05$ compared to before treatment in the same group;

\#indicated $\mathrm{P}<0.05$ comparing to the control group. 
Liping Chen et al.

Table-IV: Changes of content of inflammatory factors in serum before and after treatment.

\begin{tabular}{llcccc}
\hline Group & & TNF- $a(g / L)$ & $C R P(m g / L)$ & $s I C A M-1(n g / L)$ & $I F N-\gamma(n g / L)$ \\
\hline Treatment group & Before & $4.58 \pm 0.61$ & $59.43 \pm 7.75$ & $9.28 \pm 1.46$ & $12.54 \pm 1.86$ \\
& After & $1.77 \pm 0.26^{* \#}$ & $15.67 \pm 1.93^{* \#}$ & $3.43 \pm 0.51^{* \#}$ & $4.65 \pm 0.83^{* \#}$ \\
Control group & Before & $4.65 \pm 0.72$ & $60.15 \pm 7.86$ & $9.34 \pm 1.17$ & $12.91 \pm 2.22$ \\
& After & $2.56 \pm 0.37^{*}$ & $25.51 \pm 4.57^{*}$ & $4.96 \pm 0.78^{*}$ & $7.75 \pm 0.94^{*}$ \\
\hline
\end{tabular}

Note: ${ }^{*}$ indicated $\mathrm{P}<0.05$ comparing to before treatment in the same group;

\#indicated $\mathrm{P}<0.05$ comparing to the control group.

rale. A study shows that the progression of infantile pneumonia to severe pneumonia is related to the low specific and non-specific immune function, and the incidence of complications is high, which poses a great threat to children's life and health. ${ }^{14}$ At present, symptomatic support, antimicrobial and antiviral therapy have been widely used in clinic, but the effect is not satisfactory.

The immunoglobulin used in this study was prepared from healthy plasma. Ig G is the main component of immunoglobulin, accounting for about $90 \%$, which can prevent infection and enhance the resistance of human body. Immunoglobulin also contains a large number of specific antibodies which can resist viruses, bacteria and various pathogenic microorganisms. ${ }^{15,16}$ A study has suggested that the differentiation and maturity of B lymphocytes is inhibited and the synthesis and secretion of corresponding Ig significantly reduces in the development of severe pneumonia, which can affect the killing effect of humoral immune response on pathogens. ${ }^{17}$ In children with pneumonia, the secretion of Ig G is the most obvious, the secretion of IgA is slightly reduced, but the secretion of Ig M has no significant changes. Ig injection is mainly used to supplement Ig G in clinical treatment, which is consistent with the humoral immune characteristic of children with severe pneumonia that Ig G content is relatively low. It can effectively correct the pathological state of children with severe pneumonia whose humoral immune response is inhibited and Ig G synthesis and secretion is insufficient. ${ }^{18}$ The results of this study showed that the level of $\mathrm{Ig} G$ in the treatment group was significantly higher than that in the control group, and the improvement of Ig $\mathrm{A}$ and Ig $\mathrm{M}$ levels was also greater than that in the control group, which indicated that intravenous injection of Ig could rapidly increase the level of $\mathrm{Ig}$ in children with severe pneumonia, enhance immune function and accelerate the clearance of pathogenic microorganisms in the respiratory tract, which was consistent with the results of Zhou et al. ${ }^{19}$ The results of the present study showed that the total effective rate of the treatment group was significantly higher than that of the control group, and the disappearance time of cough, rales and fever and improvement time of cardiac failure of the treatment group were shorter than those of the control group. It indicated that Ig adjuvant therapy could improve the treatment effect and prognosis of severe pneumonia and was conducive to the relief of clinical symptoms and recovery of signs, which was consistent with the research results of previous studies. ${ }^{20,21}$

Activation of systemic inflammatory response is an important pathological feature in children with severe pneumonia. A large number of inflammatory factors such as TNF- $\alpha$, CRP, sICAM-1 and IFN- $\gamma$ are secreted into the blood circulation. TNF- $\alpha$ can mediate the cascade reaction of inflammation and kill pathogens by increasing the release of proteolytic enzymes and neutrophil degranulation. ${ }^{22} \mathrm{CRP}$ is an acute phase reactant which is synthesized by the liver; pathogen infection of human body can significantly promote the synthesis and secretion of CRP. sICAM-1 is a kind of adhesion molecule, which can mediate the aggregation and metastasis of inflammatory cells, promote the recruitment of inflammatory cells and the activation of inflammatory reaction in local lesions. ${ }^{23}$ IFN- $\gamma$ is secreted by NK cells and T cells, which can activate monocyte macrophages and significantly enhance the phagocytosis function of pathogen. ${ }^{24}$ The results of this study showed that the serum levels of TNF-a, CRP, sICAM-1 and IFN- $\gamma$ in the treatment group were significantly lower than those in the control group, suggesting that Ig adjuvant treatment could significantly reduce the synthesis and secretion of multiple inflammatory factors to inhibit inflammatory reaction and improve the effect of clinical treatment.

\section{CONCLUSION}

In the treatment of children with severe pneumonia, intravenous injection of Ig on the basis of conventional treatment has a sound effect. The therapy can effectively improve the treatment effect, accelerate the improvement of symptoms, enhance the immune functions of body and inhibit 
inflammatory reaction. But the size of samples was small and the observation time was short; hence the safety of medication has not been considered, which needs to be further studied in larger sample size in the future.

Acknowledgement: Project for Medical Science and Technology Development of Shandong Province, 2013WS0097.

\section{Declaration of interest: None.}

Grant Support \& Financial Disclosures: None.

\section{REFERENCES}

1. Huong PL, Hien PT, Lan NT, Binh TQ, Tuan DM, Anh DD. Pneumonia in vietnamese children aged 1 to 15 years due to atypical pneumonia causative bacteria: hospital-based microbiological and epidemiological characteristics. Jpn J Infect Dis. 2015;58(9):397-409. doi: 10.7883/yoken. JJID.2015.157.

2. Li J, Zhao Y, Liu Z, Zhang T, Liu C, Liu X. Clinical report of serious complications associated with measles pneumonia in children hospitalized at Shengjing hospital. Chin J Infect Dev Ctries. 2015;9(10):1139-1146. doi: 10.3855/jidc.6534.

3. Mao ZM. Efficacy analysis of intravenous immunoglobulin treatment on 36 children with severe pneumonia. Immunol J. 2013;29(7):637-638.

4. Guerra M, Crichiutti G, Pecile P, Romanello C, Busolini E, Valent $\mathrm{F}$, et al. Ultrasound detection of pneumonia in febrile children with respiratory distress:a prospective study. Eur J Pediatr 2016;175(2):163-170. doi: 10.1007/s00431-015-2611-8.

5. Li MX, Wan CM. A retrospective analysis of clinical features and death factors of infants and young children with severe pneumonia. Chin Pediatr Emerg Med. 2015;22(2):113-118. doi: 10.3760/cma.j.issn.1673-4912.2015.02.010.

6. Fischer N, Rohde $H$, Indenbirken $D$, Günther $T$, Reumann $K$ Lütgehetmann $\mathrm{M}$, et al. Rapid metagenomic diagnostics for suspectd outbreak of severe pneumonia. Emerg Infect Dis. 2014;20(6):1072-1075. doi: 10.3201/eid2006.131526.

7. Wenzei SE, Gibbs RL, Lehr MV, Simoes EAF. Respiratory outcomes in higIl-risk children 7 to 10 years after prophylaxis with respiratory syncytial virus immune globulin. Am J Med. 2002;112(8):627-633. doi: 10.1016/S0002-9343(02)01095-1.

8. Wu YJ, Gan K. Analysis on the application values of Immunoglobulin therapy for newborns with infectious pneumonia.MaternChildHealthCareChin.2015;30(7):1046-1048 doi: 10.7620/zgfybj.j.issn.1001-4411.2015.07.23.

9. Wasserman RL, Melamed I, Kobrynski L, Puck J, Gupta S, Doralt J, et al. Recombinant human hyaluronidase facilitated subcutaneous immunoglobulin treatment in pediatric patients with primary immunodeficiencies: long-term efficacy, safety and tolerability. Immunotherapy. 2016;8(10): 1175-1186. doi: 10.2217/imt-2016-0066.

10. Kamei K, Nakanishi K, Ito S, Ishikura K, Hataya H, Honda $\mathrm{M}$, et al. Risk factors for persistent proteinuria after a 2-year combination therapy for severe childhood Ig A nephropathy. Pediatr Nephrol. 2015;30(6):961. doi: 10.1007/s00467-014-3019-9.

11. Haugen J, Chandyo R, Ulak M, Mathisen M, Basnet S, Brokstad $\mathrm{KA}$, et al. 25-Hydroxy-vitamin D concentration is not affected by severe or non-severe pneumonia, or inflammation, in young children. Nutrients. 2017;9(1):52. doi: 10.3390/nu9010052.

12. Group of Respiration, Society of Pediatrics, Chinese Medical Association. Editorial committee of Chinese Journal of Pediatrics. Guidelines for management of community acquired pneumonia in children (2013 revised). Chin J Pediatrics. 2013;51(10):745-752.

13. Bárány B, Pollicott $M$, Simon K. Efficacy observation of Heparin sodium in treatment of children with severe pneumonia. Chin Mod Med. 2013;148(3):393-421.
14. Arays R, Goyal S, Jordan KM. Common variable immunodeficiency, immune thrombocytopenia, rituximab and splenectomy: important considerations. Postgrad Med. 2016;128(6):567-572. doi: 10.1080/00325481.2016.1199250.

15. Vollebregt MM, Malfroot A, De Raedemaecker M, van der Burg M, van der Werff Ten, Bosch JE. Immunodeficiency in a child with rapadilino syndrome: a case report and review of the literature. Case Reports Immunol. 2015;2015:137368. doi: $10.1155 / 2015 / 137368$

16. Youn YS, Lee SC, Rhim JW, Shin MS, Kang JH, Lee KY. Early additional immune-modulators for mycoplasma pneumoniae pneumonia in children: an observation study. Infect Chemother. 2014;46(4):239-247. doi: 10.3947/ic.2014.46.4.239.

17. Ahluwalia J, Wan J, Lee DH, Treat J, Yan AC. Mycoplasmaassociated Stevens-Johnson syndrome in children: retrospective review of patientsmanaged with or without intravenous immunoglobulin, systemic corticosteroids, or a combination of therapies. Pediatr Dermatol. 2014;31(6):664-669. doi: 10.1111/ pde.12481.

18. Waites KB, Talkington DF. Mycoplasma pneumoniae and its role as a human pathogen. Clin Microbiol Rev. 2004;17(4):697728. doi: 10.1128/CMR.17.4.697-728.2004.

19. Zhou L, Xu HS, Zhao D, Wang QG, Xie Q. Effects of immunotherapy on immune function and inflammatory factors in patients with severe pneumonia. Lab Med Clin. 2017;14(18):2658-2661.

20. He B, Bian J, Jiang Y, Feng Y. Intravenous immunoglobulin therapy in the treatment of children's severe pneumonia: a systematic review. Med J Wuhan Univ. 2013;172(2 Pt 1):690-4.

21. Kaibin PU, Huang Y, Shu C, Yan L, Han HL. Intravenous immunoglobulin in the treatment of severe adenovirus pneumonia in children: a clinical observation of 210 cases. J Clin Pediatr. 2014;32(5):449-452. doi:

22. Romanova EN, Govorin AV. TNF-a, IL-10, and eNOS gene polymorphisms in patients with influenza A/H1N1 complicated by pneumonia. Ter Arkh. 2013;85(3):58-62.

23. Dragoni S, Hudson N, Kenny BA, Burgoyne T, McKenzie JA, Gill Y, et al. Endothelial MAPKs direct ICAM-1 signaling to divergent inflammatory functions. J Immunol. 2017;198(10):4074. doi: 10.4049/jimmunol.1600823.

24. Chen YM, Huang WJ, Li SL, Liang K. Changes of IFN- $\gamma$, IL-6 and TNF- $\alpha$ levels in rats with severe pneumonia. Chin J Pathophysiol. 2007;23(3):492-494.

\section{Authors' Contribution:}

LPC \& XHQ: Study design, data collection and analysis. LPC, RYL, XDW \& BHS: Manuscript preparation, drafting and revising. LPC \& QMM: Review and final approval of manuscript.

Authors:

1. Liping Chen

Department of Pediatrics,

2. Xuehai $\mathrm{Oi}$

Department of Pediatrics,

Tai'an Maternal and Child Health Hospital,

Tai'an, 271000, China.

3. Ruiying $\mathrm{Li}$,

Department of Gynecology,

4. Xudong Wang,

Department of Pediatrics,

5. Baohai Shi,

Department of Pediatrics,

6. Qingmei Meng

Department of Pediatrics,

1,3-6: Tai'an City Central Hospital, Tai'an, 271000, China. 